\title{
Knowledge, Awareness and Practice Regarding Piezoelectric Surgery Among Dental Students
}

\author{
Pavithra H Dave ${ }^{1}$, Dhanraj Ganapathy ${ }^{2}$ and Subhashree $\mathrm{R}^{3}$ \\ ${ }^{1}$ Saveetha Dental College and Hospitals Saveetha Institute of Medical \\ and Technical Sciences Saveetha University Chennai 77, India \\ ${ }^{2}$ Professor and Head of Department Department of Prosthodontics Saveetha Dental \\ College and Hospitals Saveetha Institute of Medical and Technical Sciences Saveetha \\ University Chennai 77, India \\ ${ }^{3}$ Senior Lecturer Department of Prosthodontics Saveetha Dental College and Hospitals Saveetha \\ Institute of Medical and Technical Sciences Saveetha University Chennai 77, India
}

\section{ABSTRACT}

Piezoelectric surgery implies a minimally invasive method that decreases the risk of harm to surrounding soft tissues and significant structures such as nerves, vessels, and mucosa. The main aim of the present study is to assess the knowledge, awareness, and practice of dental students based on the usage of piezoelectric surgery. The objective of the study was to perform the knowledge, awareness, and practice of dental students based on the choice and the technique of piezoelectric surgery. A sample size of 100 dental practitioners who perform surgical procedures was considered as participants. A questionnaire comprising 10 questions on the incidence, technique, and major aspects of piezoelectric surgery was given. The subjects were made to fill the questionnaire through an online portal. The recordings were made individually by the investigator and results were analyzed. All the data was arranged in a tabulated form and analyzed. The results inferred from the study show that $68 \%$ of the participants were aware of the term piezoelectric surgery, $75 \%$ believe it was originally developed for the atraumatic cutting of bone, most of them were aware of the advantages and uses of piezoelectric surgery, 52\% were aware of Er: YAG laser is used in this technique. From the study, we can conclude that there is sufficient knowledge amongst the dental practitioners regarding choice and the technique of piezoelectric surgery

KEY WORDS: AWARENESS; DIFFICULTY; PIEZOELECTRIC; TECHNIQUES.

\section{INTRODUCTION}

Piezoelectric surgery implies a minimally invasive method that decreases the risk of harm to surrounding soft tissues

\section{ARTICLE INFORMATION}

*Corresponding Author: dhanraj@saveetha.com

Received 12th June 2020 Accepted after revision 11th August 2020 Print ISSN: 0974-6455 Online ISSN: 2321-4007 CODEN: BBRCBA

Thomson Reuters ISI Web of Science Clarivate Analytics USA and Crossref Indexed Journal

\section{Clarivate
Analytics}

NAAS Journal Score 2020 (4.31) SJIF: 2020 (7.728)

A Society of Science and Nature Publication,

Bhopal India 2020. All rights reserved.

Online Contents Available at: http//www.bbrc.in/

Doi: $h t t p: / / d x$.doi.org/10.21786/bbrc/13.7/80 and significant structures such as nerves, vessels, and mucosa. It also decreases harm to osteocytes and allows good survival of bony cells when harvesting of bone (Labanca et al., 2008). Piezoelectric surgery was initially used by oral and maxillofacial surgeons for osteotomies, though lately it is applied for specific uses in neurosurgery and orthopedics as well (Vercellotti, 2000).

In 1880 , piezoelectricity was discovered by Jacques and Curie. In 1953, in the scope of dentistry, ultrasonics set itself chiefly in periodontology and endodontics when Catuna first published the cutting effects of highfrequency sound waves towards the dental hard tissue (González-García et al., 2009).

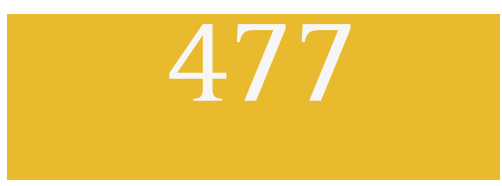


Piezoelectric devices usually consist of a handpiece and footswitch that are connected to the main power unit. This has a holder for the handpiece and contains irrigation fluids that create an adjustable jet pump removing debris from the cutting area and maintains a blood-free operating area because of cavitation of the irrigation solution giving greater visibility particularly in complex anatomical areas by dispersing coolant fluid as an aerosol (Rahnama et al., 2013) (Wallace et al., 2007). The piezoelectric system is based on the fact that certain crystalline structures such as quartz will be subject to a change in shape when placed within an electric field (Chiriac et al., 2005).

Piezoelectric equipment can be used for endodontic surgery, periodontology and implantology, scaling subgingival plaque, osteotomy and osteoplasty procedures to create the positive physiologic architecture of bone support of the involved teeth, harvesting bone blocks and bone grafting, sinus lift procedure, ridge augmentation, and ridge expansion, tooth extraction, cystectomy, maxillofacial surgery, surgical orthodontic surgery, otological surgery, neurosurgery, orthopedic, and hand surgery (Horton et al., 1975).

The advantages of the piezosurgery for augmentative purposes, sinus floor elevation carries a way the lower risk of perforation or injury to the mucous membrane since soft tissues cannot be damaged with this method (Seshan et al., 2009) (Robiony et al., 2004). The most convincing characteristics of piezoelectric bone surgery are low surgical trauma, exceptional control during surgery, and quick healing response of tissues (Schaeren et al., 2008). Clinical researches have shown the specificity and hence the technique applied with piezoelectric surgery makes it likely to advantageously utilize differences in hard and soft tissue anatomy. This not only increases treatment efficacy but it also improves postoperative recovery and healing (Vercellotti et al., 2005) (Aro et al., 1981).

Figure 1: Pie chart showing responses to the question, 'Are you aware of the term piezoelectric surgery?'. Majority of respondents reported as yes they are aware of term piezoelectric surgery $(68 \%)$.

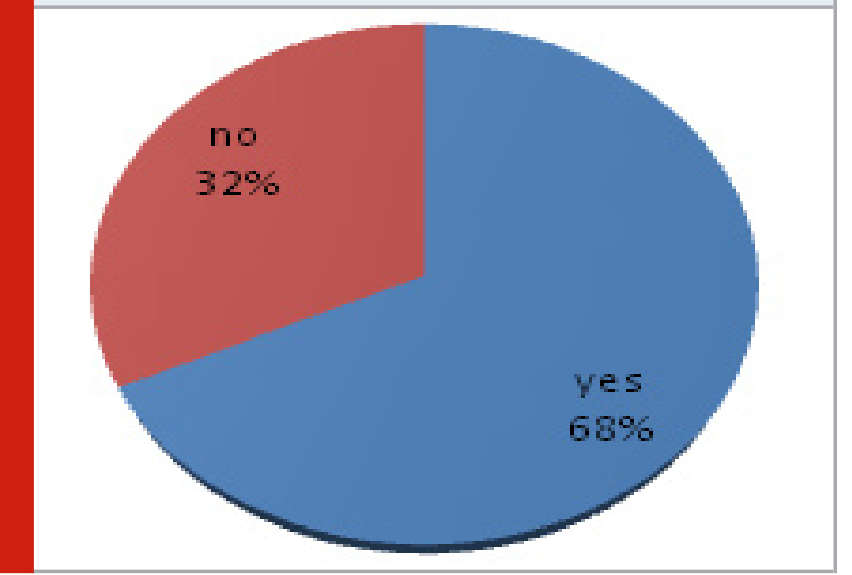

Previously our department has published extensive research on various aspects of prosthetic dentistry (Anbu et al., 2019; Ariga et al., 2018; Ashok and Ganapathy, 2019; Duraisamy et al., 2019; Ganapathy et al., 2017; Gupta et al., 2018; Jain, 2017a, 2017b; Ranganathan et al., 2017; Varghese et al., 2019; World Journal of Dentistry, 2017), this vast research experience has inspired us to research about the knowledge, awareness, and practice of dental students based on the choice and the technique of piezoelectric surgery.

Figure 2: Pie chart showing responses to the question, 'Piezosurgery device was originally developed for the atraumatic cutting of bone by way of ultrasonic vibrations? '. Majority of respondents reported as yes they are aware of atraumatic cutting of bone (75\%).

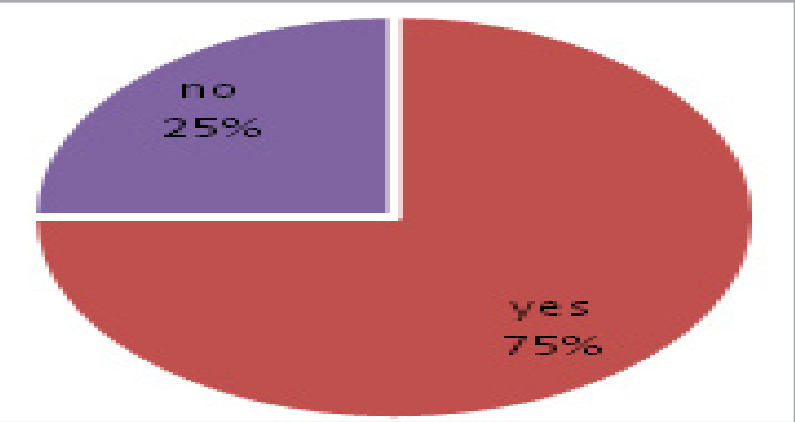

Figure 3: Bar chart showing responses to the question, 'Advantages of piezoelectric technique include? '. Majority of respondents reported all of the above- precise and selective cuttings, avoidance of thermal damage and preservation of soft-tissue structures (45\%).

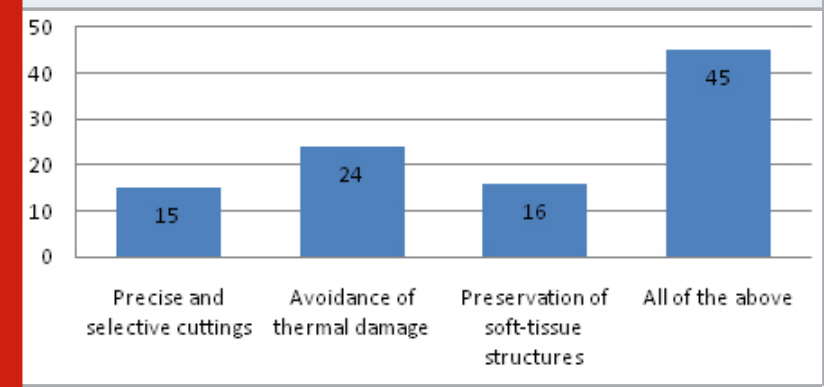

\section{MATERIAL AND METHODS}

A cross-sectional survey was conducted among dentists in a private dental college, Chennai. A structured, self administrable questionnaire consisting of ten multiple choice questions (MCQs) encompassing major aspects of piezoelectric surgery conducted through an online survey was prepared and shared among dentists, and dental students. The survey included the techniques and treatment methods, type of laser, materials, complications were distributed. The dentists were permitted to choose more than one answer, if they desired. The convenient sample size of 100 dental students and practitioners was decided and data was collected by questionnaire. The responses were tabulated and statistically analyzed. 
Questionnaire:

1) Are you aware of the term piezoelectric surgery?

A. Yes

B. No

2) Piezosurgery device was originally developed for the atraumatic cutting of bone by way of ultrasonic vibrations?

A. Yes

B. No

3) Advantages of piezoelectric technique include?

A. Precise and selective cuttings

B. Avoidance of thermal damage

C. Preservation of soft-tissue structures

D. All of the above

4) Approaches are more efficient in reducing postoperative complications compared to the conventional surgeries.

A. Agree

B. Disagree

5) Piezo surgery is used for the following treatments?

A. Harvesting bone blocks and bone grafting

B. Bone osteotomy or corticotomy

C. Tooth extraction

D. Sinus lift procedure

E. Cystectomy

F. All of the above

6) Lasers which are commonly used in piezoelectric surgery?

A. Er:YAG (2940 nm)

B. Er,Cr:YSGG (2780 nm)

7) Application of mechanical stress on the piezoelectric material leads to generation of electricity. This is known as?

A. Direct piezo effect

B. Inverse piezo effect

8) Application of electricity on the piezoelectric marterial leads to physical deformation and thus causes generation of mechanical force. This is known as?

A. Direct piezo effect

B. Inverse piezo effect

9) Insert tips of Gold colour are used to treat

A. Bone

B. Soft tissues

10) Insert tips of stainless steel are used to treat

A. Bone

B. Soft tissues

\section{RESULTS AND DISCUSSION}

The survey was taken up by 100 people who included the dental students and dentists. The results obtained were tabulated, and bar charts were prepared to analyze the result. Among the participants of this study we observed that, figure 1 shows the majority of respondents reported as yes they are aware of term piezoelectric surgery (68\%). Figure 2 shows the majority of respondents reported as yes they are aware of atraumatic cutting of bone (75\%). Figure 3 shows the majority of respondents reported all of the above- precise and selective cuttings, avoidance of thermal damage and preservation of soft-tissue structures $(45 \%)$. Figure 4 shows the majority of respondents agreed to this question (89\%). Figure 5 shows the majority of respondents reported all of the above- harvesting bone blocks and bone grafting, bone osteotomy or corticotomy, tooth extraction, sinus lift procedure and cystectomy (30\%).

Figure 4: Bar chart showing responses to the question, 'Approaches are more efficient in reducing postoperative complications compared to the conventional surgeries?' Majority of respondents agreed to this question (89\%).

Disagree

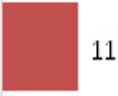

Agree



Figure 5: Bar chart showing responses to the question, 'Piezo surgery is used for the following treatments? '. Majority of respondents reported all of the aboveharvesting bone blocks and bone grafting, bone osteotomy or corticotomy, tooth extraction, sinus lift procedure and cystectomy (30\%).

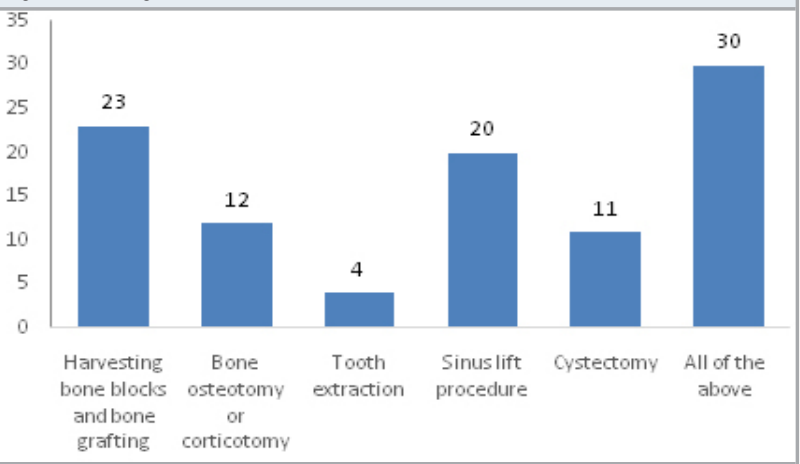

Figure 6 shows the majority of respondents reported Er:YAG (2940 $\mathrm{nm}$ ) as the most commonly used laser (52\%). Figure 7 shows the majority of respondents reported the direct piezo effect (60\%). Figure 8 shows the majority of respondents reported an indirect piezo effect (65\%). Figure 9 shows the majority of respondents reported gold tips are used for treatment of bone (63\%). Figure 10 shows the majority of respondents reported stainless steel tips are used for treatment of soft tissues (59\%).

Based on the above results, 68\% of the participants were aware of the term piezoelectric surgery which is gaining popularity in the field of dentistry in recent years. Regarding the atraumatic cutting of bone, 75\% of the population was aware of it. In a study conducted by Wallace et al, it was suggested for the utilization of piezoelectric surgery, rather than rotary diamond burs, for lateral window preparation and hence reduction in 
intraoperative complications (Wallace et al., 2012) (Lee et al., 2007).

Figure 6: Bar chart showing responses to the question, 'Lasers which are commonly used in piezoelectric surgery? '. Majority of respondents reported Er:YAG (2940 nm) as the most commonly used laser (52\%).

Er:YAG $(2940 \mathrm{~nm}) \quad \mathrm{Er}, \mathrm{Cr}: \mathrm{YSGG}(2780 \mathrm{~nm})$

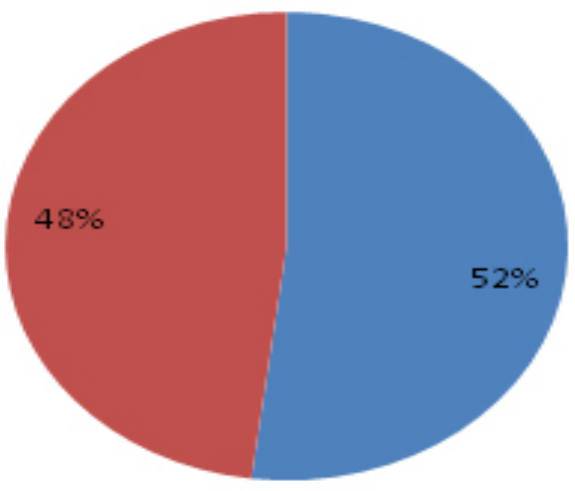

Figure 7: Bar chart showing responses to the question, 'Application of mechanical stress on the piezoelectric material leads to generation of electricity. This is known as? '. Majority of respondents reported the direct piezo effect $(60 \%)$.

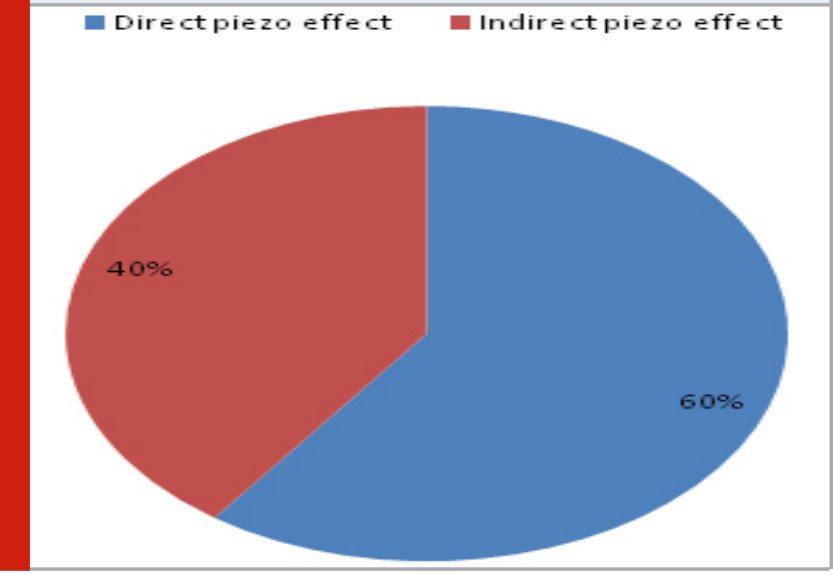

Advantages of piezoelectric surgery include avoidance of thermal damage, precise and selective cutting, and preservation of soft tissue structures and were opted by $45 \%$ of the participants which is in accordance with a study done by Thomas et al in 2017 (Thomas et al., 2017). In this study, $89 \%$ of the population believed that postoperative complication are reduced by the usage of this technique. In a study done by Shirota et al, the effectiveness of piezoelectric surgery in reducing surgical complications after bilateral sagittal split osteotomy was shown (Shirota et al., 2014).

Piezosurgery is used for the following treatmentsHarvesting bone blocks and bone grafting, Bone osteotomy or corticotomy, Tooth extraction, Sinus lift procedure, Cystectomy which $30 \%$ of the population selected for all of the above treatments. The use of Piezoelectric osteotomy in craniofacial surgery was suggested in a study done by Gleizal et al (Gleizal et al., 2007). Lasers that are commonly used in piezoelectric surgery are Er: YAG (2940 nm) opted by 52\% followed by Er, Cr: YSGG (2780 nm) opted by 48\%. The use of Er: YAG laser for impacted third molar surgery was shown in a study done by Keyhan S0 et al in December 2019 (Keyhan et al., 2019). Application of mechanical stress on the piezoelectric material leads to the generation of electricity and this is known as the direct piezo effect, opted by $60 \%$ of the participants. Application of electricity on the piezoelectric material leads to physical deformation and thus causes the generation of mechanical force and this is known as the indirect piezo effect (65\%). The relationship between direct and converse piezoelectric effect in a nanoscale electromechanical contact was reviewed by Kalinin et al (Kalinin and Gruverman, 2007).

Figure 8: Bar chart showing responses to the question, 'Application of electricity on the piezoelectric material leads to physical deformation and thus causes generation of mechanical force. This is known as? ' Majority of respondents reported an indirect piezo effect (65\%).

- Directpiezo effect Indirectpiezo effect

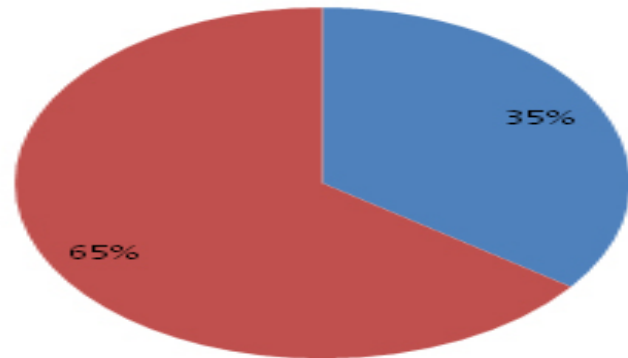

Figure 9: Bar chart showing responses to the question, Insert tips of Gold colour are used to treat?'. Majority of respondents reported gold tips are used for treatment of bone $(63 \%)$.

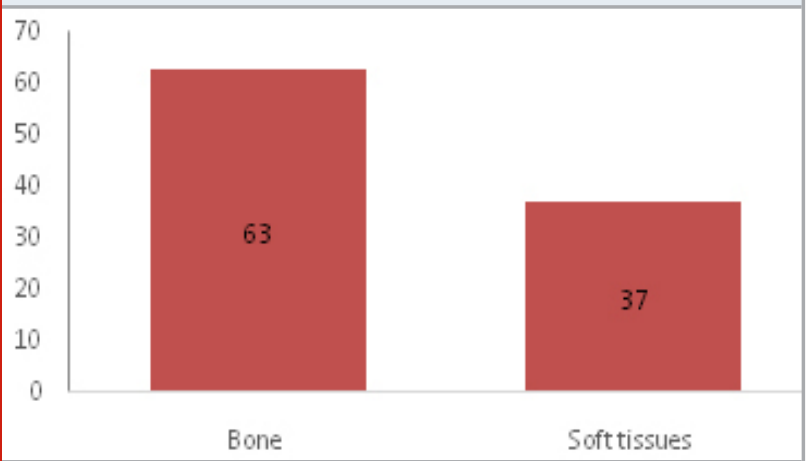

Insert tips of gold are used to treat bone (63\%). Insert tips of stainless steel are used to treat soft tissues (59\%). Most of the periodontal and oral surgical procedures require bone cutting. Although the traditional method of bone surgery provides better predictability and ease 
of application, they have several drawbacks such as a high heat generation, damage to the cells, necrosis of the tissues. To overcome these factors the piezoelectric surgery has been introduced which causes micrometric and selective cutting creates a clear-cutting field and excellent tissue healing (Chandra et al., 2017). As a result, periodontal and implant surgical techniques can be performed with greater ease and safety. The better clinical results are due to its positive effects on the first phases of bony healing; it induces an earlier increase in bone morphogenetic proteins, controls the inflammatory process (Vignesh and Thamariselvan, 2016). With the advancement in the field of dentistry, an implantsupported prosthesis is no more a big challenge and hence piezoelectric surgery has paved the way for direct sinus lift with immediate implant placement Maxillary sinus lift with an accompanying bone graft serves as a simple, widely used procedure (Vidhya and Nesappan, 2016).

Figure 10: Bar chart showing responses to the question, 'Insert tips of stainless steel are used to treat? '. Majority of respondents reported stainless steel tips are used for treatment of soft tissues (59\%).

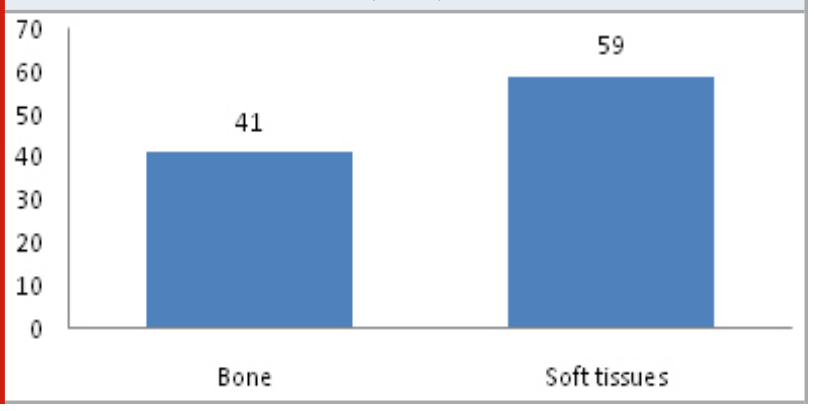

\section{CONCLUSION}

As per the data, though the knowledge, awareness and practice among the dental practitioners regarding the piezoelectric surgery is adequate, there is a need for an update regarding the correct and prudent application of these critically important perspectives in dentistry for providing better treatment without any complications.

\section{ACKNOWLEDGEMENTS}

The authors would like to thank Saveetha Dental College and Hospitals for providing a platform to conduct the study.

Conflicts of Interest: The authors declare no conflicts of interest.

\section{REFERENCES}

Anbu RT, Suresh V, Gounder R, et al. (2019) Comparison of the Efficacy of Three Different Bone Regeneration Materials: An Animal Study. European journal of dentistry 13(1): 22-28.

Ariga P, Nallaswamy D, Jain AR, et al. (2018) Determination of Correlation of Width of Maxillary
Anterior Teeth using Extraoral and Intraoral Factors in Indian Population: A Systematic Review. World Journal of Dentistry 9(1): 68-75.

Aro H, Kallioniemi H, Aho AJ, et al. (1981) Ultrasonic Device in Bone Cutting:A Histological and Scanning Electron Microscopical Study. Acta Orthopaedica Scandinavica. DOI: 10.3109/17453678108991750.

Ashok V and Ganapathy D (2019) A geometrical method to classify face forms. Journal of oral biology and craniofacial research 9(3): 232-235.

Chandra B, N NW and Praksh S (2017) PIEZOSURGERY: A versatile tool in periodontology and oral implantology. International Journal of Dental Research. DOI: 10.14419/ ijdr.v5i2.7967.

Chiriac G, Herten M, Schwarz F, et al. (2005) Autogenous bone chips: influence of a new piezoelectric device (Piezosurgery) on chip morphology, cell viability and differentiation. Journal of clinical periodontology 32(9): 994-999.

Duraisamy R, Krishnan CS, Ramasubramanian H, et al. (2019) Compatibility of Nonoriginal Abutments With Implants: Evaluation of Microgap at the ImplantAbutment Interface, With Original and Nonoriginal Abutments. Implant dentistry 28(3): 289-295.

Ganapathy DM, Kannan A and Venugopalan S (2017) Effect of Coated Surfaces influencing Screw Loosening in Implants: A Systematic Review and Meta-analysis. World Journal of Dentistry 8(6): 496-502.

Gleizal A, Bera J-C, Lavandier B, et al. (2007) Piezoelectric osteotomy: a new technique for bone surgery-advantages in craniofacial surgery. Child's Nervous System. DOI: 10.1007/s00381-006-0250-0.

González-García A, Diniz-Freitas M, Somoza-Martín M, et al. (2009) Ultrasonic osteotomy in oral surgery and implantology. Oral surgery, oral medicine, oral pathology, oral radiology, and endodontics 108(3): 360-367.

Gupta P, Ariga P and Deogade SC (2018) Effect of Monopoly-coating Agent on the Surface Roughness of a Tissue Conditioner Subjected to Cleansing and Disinfection: A Contact Profilometric Study. Contemporary clinical dentistry 9(Suppl 1): S122S126.

Horton JE, Tarpley TM Jr and Wood LD (1975) The healing of surgical defects in alveolar bone produced with ultrasonic instrumentation, chisel, and rotary bur. Oral surgery, oral medicine, and oral pathology 39(4): 536-546.

Jain AR (2017a) Clinical and Functional Outcomes of Implant Prostheses in Fibula Free Flaps. World Journal of Dentistry 8(3): 171-176.

Jain AR (2017b) Prevalence of Partial Edentulousness and Treatment needs in Rural Population of South India. World Journal of Dentistry 8(3): 213-217.

Kalinin SV and Gruverman A (2007) Scanning 
Probe Microscopy: Electrical and Electromechanical Phenomena at the Nanoscale. Springer Science $\&$ Business Media.

Keyhan SO, Fallahi HR, Cheshmi B, et al. (2019) Use of piezoelectric surgery and Er:YAG laser:which one is more effective during impacted third molar surgery? Maxillofacial plastic and reconstructive surgery 41(1): 29.

Labanca M, Azzola F, Vinci R, et al. (2008) Piezoelectric surgery: twenty years of use. The British journal of oral Et maxillofacial surgery 46(4): 265-269.

Lee H-J, Ahn M-R and Sohn D-S (2007) Piezoelectric distraction osteogenesis in the atrophic maxillary anterior area: a case report. Implant dentistry 16(3): 227-234.

Rahnama M, Czupkałło L, Czajkowski L, et al. (2013) The use of piezosurgery as an alternative method of minimally invasive surgery in the authors' experience. Wideochirurgia i inne techniki maloinwazyjne = Videosurgery and other miniinvasive techniques 8(4): 321-326.

Ranganathan H, Ganapathy DM and Jain AR (2017) Cervical and Incisal Marginal Discrepancy in Ceramic Laminate Veneering Materials: A SEM Analysis. Contemporary clinical dentistry 8(2): 272-278.

Robiony M, Polini F, Costa F, et al. (2004) Piezoelectric bone cutting in multipiece maxillary osteotomies. Journal of oral and maxillofacial surgery: official journal of the American Association of Oral and Maxillofacial Surgeons 62(6): 759-761.

Schaeren S, Jaquiéry C, Heberer M, et al. (2008) Assessment of nerve damage using a novel ultrasonic device for bone cutting. Journal of oral and maxillofacial surgery: official journal of the American Association of Oral and Maxillofacial Surgeons 66(3): 593-596.

Seshan H, Konuganti K and Zope S (2009) Piezosurgery in periodontology and oral implantology. Journal of Indian Society of Periodontology 13(3): 155-156.

Shirota T, Kamatani T, Yamaguchi T, et al. (2014) Effectiveness of piezoelectric surgery in reducing surgical complications after bilateral sagittal split osteotomy. The British journal of oral \&t maxillofacial surgery 52(3): 219-222.

Thomas M, Akula U, Ealla KKR, et al. (2017) Piezosurgery: A Boon for Modern Periodontics. Journal of International Society of Preventive \& Community Dentistry 7(1): 1-7.

Varghese SS, Ramesh A and Veeraiyan DN (2019) Blended Module-Based Teaching in Biostatistics and Research Methodology: A Retrospective Study with Postgraduate Dental Students. Journal of dental education 83(4): 445-450.

Vercellotti T (2000) Piezoelectric surgery in implantology: a case report--a new piezoelectric ridge expansion technique. The International journal of periodontics $A$ restorative dentistry 20(4): 358-365.

Vercellotti T, Nevins ML, Kim DM, et al. (2005) Osseous response following resective therapy with piezosurgery. The International journal of periodontics \& restorative dentistry 25(6): 543-549.

Vidhya G and Nesappan T (2016) A piezoelectric surgery for direct sinus lift with immediate implant placement. Journal of Dental Implants 6(2). Medknow Publications and Media Pvt. Ltd.: 79.

Vignesh VK and Thamariselvan (2016) Piezo Electric Surgery in Periodontal Therapy. Research Journal of Pharmacy and Technology. DOI: 10.5958/0974360x.2016.00013.5.

Wallace SS, Mazor Z, Froum SJ, et al. (2007) Schneiderian membrane perforation rate during sinus elevation using piezosurgery: clinical results of 100 consecutive cases. The International journal of periodontics \& restorative dentistry 27(5): 413-419.

Wallace SS, Tarnow DP, Froum SJ, et al. (2012) Maxillary sinus elevation by lateral window approach: evolution of technology and technique. The journal of evidencebased dental practice 12(3 Suppl): 161-171.

World Journal of Dentistry (2017) Evaluation of Corrosive Behavior of Four Nickel-chromium Alloys in Artificial Saliva by Cyclic Polarization Test:An in vitro Study. 8(6): 477-482. 